\title{
LOGÍSTICA REVERSA NA INDÚSTRIA METALMECÂNICA: 0 CASO DAS INDÚSTRIAS EM BLUMENAU, POMERODE E GASPAR (SC)
}

\author{
REVERSE LOGISTICS IN THE MACHINERY INDUSTRY: THE CASE OF THE INDUSTRIES IN \\ BLUMENAU, POMERODE AND GASPAR (SC)
}

\author{
LUIZ BERNARDO BRAUN PREBIANCA | FURB \\ JOEL DIAS DA SILVA, Dr.|FURB
}

\begin{abstract}
RESUMO
A atual preocupação com meio ambiente fez com que as indústrias buscassem o atendimento de normas, padrões e especificações impostas pelo governo e pela sociedade, visando minimização de impactos ambientais. Dessa forma, o estudo teve como objetivo analisar as práticas de Logística Reversa na indústria metalmecânica de grande e médio porte dos municípios de Blumenau, Pomerode e Gaspar (SC) associadas ao SIMMMEB, por meio da análise do grau de transmissão do conhecimento sobre o tema entre empresa-colaborador e avaliações das práticas realizadas pelas empresas. Refere-se à pesquisa aplicada com abordagem quantitativa e método de pesquisa qualitativa. A coleta de dados foi realizada por meio da aplicação de questionário obtendo-se $100 \%$ de respostas aptas, contando com 15 empresas avaliadas. Os principais resultados obtidos foram a vulnerabilidade de conhecimento transmitido sobre Logística Reversa e Remanufatura, boa adesão a reutilização de embalagens e alto índice de destinação de resíduos a mercados secundários. A partir destes, possibilitou-se concluir que as empresas não possuem conhecimento suficiente para gerar iniciativas estruturadas que englobem as principais práticas da logística reversa.
\end{abstract}

PALAVRAS-CHAVE: Indústria Metalmecânica. Resíduos Industriais. Logística Reversa. Reciclagem. Sustentabilidade.

\begin{abstract}
The current concern with the environment has led industries to seek compliance with norms, standards and specifications imposed by the Government and by society, aiming to minimize environmental impacts. Thus, the study aimed to analyze reverse logistics practices in the large and medium-sized machinery industry in the municipalities of Blumenau, Pomerode and Gaspar (SC) associated with SIMMMEB, through the analysis of the degree of knowledge transmission on the theme between company-collaborator and evaluations of the practices carried out by the companies. Refers to applied research with a quantitative approach and qualitative research method. Data collection was performed through the application of a questionnaire, obtaining $100 \%$ of suitable answers, with 15 companies evaluated. The main results obtained were the vulnerability of knowledge transmitted about Reverse Logistics and Remanufacturing, good adhesion to packaging reuse and a high rate of waste disposal in secondary markets. From these, it was possible to conclude that the companies do not have enough knowledge to generate structured initiatives that encompass the main practices of reverse logistics.
\end{abstract}

KEY WORDS: Machinery Industry. Industrial Waste. Reverse Logistics. Recycling. Sustainability. 


\section{INTRODUÇÃO}

O termo metalmecânico é amplamente utilizado para designar "empresas e indústrias com processos metalúrgicos e de fabricação mecânica, cujo objetivo principal é a transformação de metais" (OLIVEIRA et al., 2012). Uma unidade metalmecânica integra empresas destinadas às transformações intermediárias como as de fundição, forjaria, corte e soldagem, como também as voltadas a produtos como bens de consumo, equipamentos, máquinas e veículos (MACEDO; CAMPOS, 2001).

No Estado de Santa Catarina, destaque na economia do País, tendo alcançado o segundo lugar por participação no PIB - Produto Interno Bruto, com 27\% (FIESC, 2020), especialmente no Vale do Itajaí, que apresentou a maior participação no PIB Catarinense (33\%), é grande a representatividade do segmento metalmecânico. Por exemplo, o número de empresas de médio e grande portes, no segmento metalmecânico (56 empresas) é maior do que as dos setores têxtil (53) e de vestuário (53) (FIESC, 2015).

Apesar desta representatividade e importância econômica e social, outros desafios têm-se apresentado às indústrias deste segmento: a produção crescente de resíduos industriais. Dentre tais resíduos, estão incluídas sobras de processos industriais, aparas, rebarbas, cavacos e/ou peças obsoletas, com valor agregado e com características que lhes conferem periculosidade. $E$, por conta disto, não poderão ser descartados sem tratamento prévio (FIESP, 2020; ABNT, 2004).

Dependendo de suas características, a partir das orientações preconizadas na Política Nacional de Resíduos Sólidos, a Lei 12.305 (BRASIL, 2010), existe a exigência de implementação de logística reversa para uma diversidade de produtos. Há também a necessidade de especial atenção quanto à possibilidade de seu aproveitamento, diminuindo-se, desta forma, os custos que, futuramente, aparecerão relacionados ao seu descarte e disposição final adequados, conforme Amaomo et al., (2014).

Neste contexto, Reis et al., (2009) relembram que as sucatas são provenientes de sobras de processos industriais, e que estas, pelas suas características, não poderão ser aproveitadas no processo de fabricação. Contudo, como suas características físico-químicas presentes permanecem inalteradas, é possível realizar a reciclagem delas. Os autores destacam que as sucatas provenientes de obsolescência ainda são aptas ao uso, enquanto aquelas provenientes de produtos no fim de sua vida útil serão materiais propícios para descarte.

Por outro lado, ao considerar a aplicabilidade dos conceitos que serão abordados (i.e., análise de práticas de logística reversa), o segmento metal mecânico é caracterizado como mais apto para a realização do estudo, visto que os seus resíduos sólidos (sobras e peças obsoletas) exigem soluções técnicas e economicamente viáveis (FIESP, 2020). Por causa disso, muitas organizações passaram a repensar suas posições no mercado, reformulando estratégias e reestruturando seu processo de negócio (LEE; LAM, 2012).

Alinhadas com estas modificações, iniciativas envolvendo a implementação e práticas de logística reversa passaram a ser frequentes no meio industrial.

Objetiva-se, portanto, analisar as práticas de logística reversa implementadas na indústria metalmecânica nos municípios de Blumenau, Pomerode e Gaspar, associadas ao Sindicato das Indústrias Metalúrgicas, Mecânicas e do Material Elétrico de Pomerode, Blumenau e Gaspar - SIMMMEB, criado na década de 1950, com a determinação de fortalecer o setor e contribuir para o desenvolvimento social e econômico. De modo específico, busca-se: 1) analisar, nas organizações estudadas, o grau de transmissão do conhecimento sobre temas importantes do assunto aos colaboradores, 2) analisar o grau de aplicação de ações referentes à logística reversa, e por fim, 3) identificar oportunidades de melhorias nas situações diante das iniciativas de logística reversa nas empresas objeto de estudo.

\section{EMBASAMENTO TEÓRICO}

\subsection{A dimensão ambiental e a indústria metalmecânica}

Os resíduos produzidos neste segmento contemplam altas concentrações de metais e, se dispostos de forma inadequada no meio ambiente, existe a possibilidade de agregação dos mesmos a outros elementos neles presentes, dando origem à outras substâncias que, por si só, poderão abalar o conjunto biótico e com isto comprometer a saúde humana (BENNEMANN, 2012).

Conforme ressalta Silva (2013), no caso de gerenciamento inadequado, os resíduos sólidos poderão resultar em expressivos danos ambientais, seja qual for a atividade (industrial, comercial ou doméstica). Mesmo compreendendo a produção de resíduos, a autora salienta que, "por um longo período" o país não possuía sequer uma lei regulamentadora de resíduos sólidos e que, "após 20 anos tramitando no Congresso Nacional, em 2010, foi deferida a Política Nacional de Resíduos Sólidos (PNRS) pela Lei 12.305."

Em épocas de globalização e alto consumo, a sociedade e o governo tendem a cobrar as questões ambientais das empresas conforme as leis dispostas, para determinar 
limites no que se diz respeito a emissões de resíduos (BENNEMANN, 2012). Contudo, o autor destaca a obrigação de atuar na causa do problema, que neste caso é a geração de resíduos, destacando também que "a implantação de processos de gestão ambiental, como os descritos no conjunto de normas da série NBR ISO 14.000, têm sido ferramentas eficientes para respostas das indústrias a estas exigências".

Neste sentido, empresas que tomam iniciativa se destacam no mercado, e como discorre Araújo (2004), "pode-se afirmar que a maior parte das empresas instaladas no Brasil e ligadas ao mercado internacional tem como demanda competitiva ou até mesmo de sobrevivência, a adoção de algum tipo de gestão ambiental". O autor ainda acrescenta que, "por terem razões mercadológicas mais fortes para investirem no meio ambiente, acabam sendo pioneiras."

\subsection{Implementação da logística reversa em segmentos industriais}

Pereira et al., (2012) acrescentam que a Logística Reversa integra a concepção de logística tradicional, porém, com uma abordagem diferenciada. Nesta, priorizar-se-ão o reuso e correta destinação de produtos e embalagens, reciclagem, redução do uso de matéria prima e produção de energia.

Corrêa (2013), por exemplo, ao comparar logística tradicional e a logística reversa, menciona que ambas se assemelham por utilizarem o fluxo de informação e mercadoria. Contudo, diferenciam-se pelo sentido contrário ao da cadeia comum de suprimento. Desta forma, reforça-se a importância de que outros agentes utilizem das práticas sustentáveis para efetivar o real retorno de materiais e resíduos à empresa.

Quanto às práticas de logística reversa, Jabbour et al., (2013, apud FRASCARELI, 2014) sintetizam-nas em ações de reuso, descarte, separação adequada dos resíduos nos pontos onde são produzidos. Os autores destacam também a responsabilidade compartilhada pelo ciclo de vida do produto, destinando-os adequadamente, e valorizando-os quando possível.

Contudo, relatam-se barreiras para a materialização de práticas de logística reversa nas organizações. Conforme pontua Comper (2017), estas poderão ser:

- Gerencial: que engloba possíveis faltas de atenção, investimentos, métricas, planejamento bem como resistência da alta gestão e falta de importância dada

- Financeira/econômica: falta de recursos, percepções de lucro e economia

- Política: falhas nas legislações, políticas e informalidades
- Infraestrutura: falta de instalações físicas, sistemas e tecnologias

- Mercado: incertezas de demandas e qualidades em devolução, falta de informações aos clientes e má aceitação de produtos remanufaturados

- Socioambiental: falta de consciência, cultura e comportamentos proativos

Em contrapartida, Behdad e Wang (2016) apontam fatores de motivação para uso da Logística Reversa que podem ser levados em consideração para aplicação da mesma. Estes fatores são separados pelos autores em fatores externos: legislação, econômico, consciência ambiental. E fatores internos: competência de gestão, requisitos tecnológicos, importância estratégica e consideração financeira.

Batista (2014) esclarece que, o ato de transformar resíduo em coproduto, tem sido tratado, em muitas organizações como uma estratégia de negócio. Neste caso, utilizam-se resíduos para fabricação de novos produtos, com valor no mercado ou para fonte de energia. Nesta perspectiva, considerando-se conjuntamente as variáveis sociais, ambientais e econômicas ("tripé da sustentabilidade") na gerência de resíduos, pode torná-la um negócio potencial.

A reciclagem na indústria ajuda a minimizar o lançamento de poluentes ao meio ambiente, a utilização de recursos naturais, e a criação de empregos nas áreas de coleta e processamento (INSTITUTO AÇO BRASIL, 2018). $\mathrm{O}$ relatório destacou as principais iniciativas comumente adotadas pela indústria:

- Redução: minimização da energia e matéria prima consumida na produção de produtos (aços mais finos e mais resistentes)

- Reutilização: reuso de insumos já utilizados (pós uso)

- Reciclagem: Recuperação do insumo/resíduo para transformá-lo em matéria prima

- Remanufatura: transformação em novos os produtos que possuem defeitos ou foram utilizados (ciclo de vida novo ao produto)

Neste sentido, de acordo com o SENAI Paraná (2014), os materiais recicláveis, provenientes do setor metalmecânico, no final de sua vida útil, quando descartados pelos consumidores podem retornar ao processo produtivo como matéria prima, após passar por um conjunto de ações, meios de destinação e procedimentos referentes a logística reversa. O relatório ainda enfatiza a utilização de reutilização (otimizar o uso do material antes da disposição final e recolocá-lo no processo produtivo) e reciclagem (aproveitar o material que seria descartado e utilizá-lo no processo de fabricação) como práticas referentes a Logística Reversa. 


\section{METODOLOGIA}

Pesquisa aplicada com abordagem quantitativa, em que se objetiva mensurar variáveis pré-determinadas na busca de verificar e expor suas influências sobre outras variáveis por análises estatísticas.

Quanto aos objetivos do projeto, o método de pesquisa descritiva foi adotado, pois propõe-se a revelar problemas com base em dados coletados (CHIZZOTTI, 2010). A partir destes, será possível promover possíveis soluções dos problemas identificados no projeto ou oportunidades de melhoria.

Em relação aos procedimentos, elaborou-se um questionário como instrumento de pesquisa, de modo a subsidiar a organização de um banco de dados extraídos da amostra. Este método mostra-se adequado devido a sua possibilidade de quantificar e processar as variáveis coletadas no estudo (DELALIBERA; LIMA; TURRIONI, 2015).

\subsection{Materiais}

O questionário, instrumento de pesquisa utilizado, foi desenvolvido com o emprego de uma escala psicométrica (Escala Likert) com 5 níveis de respostas pré-definidas, sendo eles: 1 correspondendo a "discordo totalmente" até 5 para "concordo totalmente".

O formulário foi desenvolvido na plataforma Google Forms, encaminhado via e-mail para profissionais responsáveis pelos setores técnico ambiental e/ou logístico. Com intuito de qualificar os respondentes, um primeiro contato foi realizado por meio da plataforma profissional Linkedln, para selecionar os perfis aptos à pesquisa. Após a coleta dos dados, o software Microsoft Excel ${ }^{\oplus}$ foi utilizado para compilação e interpretação estatística.

\subsection{Método}

As etapas da pesquisa seguiram as informações representadas no fluxograma metodológico apresentado na Figura 1.

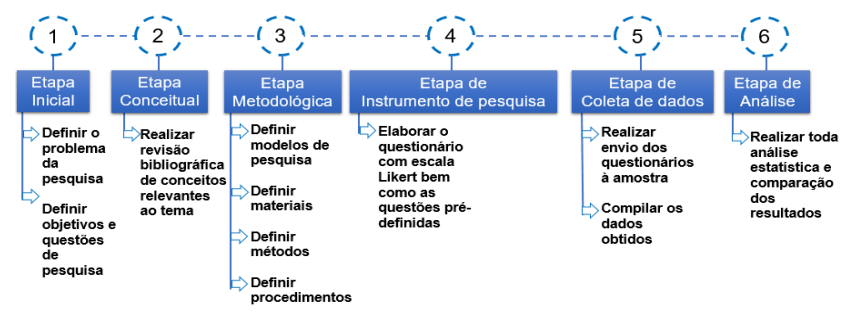

Figura 1. Fluxograma metodológico da pesquisa Fonte: Dos Autores, (2020)

\subsection{Coleta e tratamento dos dados}

A coleta de dados foi realizada no segmento metalmecânico, em empresas de médio e grande porte dos municípios de Blumenau, Pomerode e Gaspar (SC), cuja relação fora disponibilizada pelo SIMMMEB, sindicato patronal que as congrega. A entidade disponibilizou o seu Relatório de Atividades, referente ao ano de 2019, e a partir deste, contabilizaram-se 15 empresas, sendo 4 de grande e 11 de médio porte, associadas ao sindicato e aptas para participação na pesquisa.

O questionário, para fins avaliativos das práticas de logística reversa, foi embasado no levantamento teórico realizado, com perguntas organizadas em três macro tópicos e respectivas ações associadas, conforme exposto na Quadro 1.

Além disto, foi adicionado um tópico para avaliação do conhecimento transmitido das empresas aos colaboradores referentes aos termos Logística Reversa, Reciclagem, Remanufatura e Reutilização e uma pergunta aberta sobre iniciativas sobre Logística Reversa tomada pela empresa avaliada.

\begin{tabular}{|l|l|}
\hline PRÁTICAS DE LR & AÇõES ASSOCIADAS \\
\hline \multirow{4}{*}{ Reciclagem } & Uso de matéria prima secundária \\
\cline { 2 - 2 } & Transformação de resíduos sólidos \\
\cline { 2 - 2 } & Utilização de resíduos sólidos \\
\hline \multirow{5}{*}{ Remanufatura } & Assistência técnica \\
\cline { 2 - 2 } & Peças sobresalentes \\
\cline { 2 - 2 } & Recondicionamento \\
\cline { 2 - 2 } & Reparo/manutenção \\
\hline & reaproveitamento de resíduos \\
\cline { 2 - 2 } & reaproveitamento de bens usados \\
\cline { 2 - 2 } & Destinação a mercado secundário \\
\cline { 2 - 2 } & Aproveitamento de componentes/peças \\
\cline { 2 - 2 } & reaproveitamento de embalagens \\
\hline
\end{tabular}

Quadro 1. Macrotópicos orientadores do instrumento de pesquisa Fonte: Dos Autores, (2020)

No que se refere ao tratamento dos dados obtidos da aplicação do questionário no universo, o software Microsoft Excel ${ }^{\oplus}$ foi utilizado para compilação e análise da massa de resultados. Para a avaliação utilizou-se a média dos dados de cada pergunta, sendo representadas graficamente. Visando melhor acurácia da análise, a massa de dados contou com 100\% do universo de pesquisa aplicado, com a utilização de todas as informações na íntegra, sem exclusão ou modificação.

\section{RESULTADOS E DISCUSSÃO}

\subsection{Análise do Conhecimento transmitido das empresas aos colaboradores}

Neste primeiro macro tópico, buscou-se avaliar a integração de conhecimento acerca do tema Logística Reversa nas empresas pesquisadas, e entender como este conhecimento é transmitido de fato. 
Observa-se inicialmente, conforme apresentado na Figura 2 que, de modo geral, a maior parte dos colaboradores possui mais conhecimento sobre os termos reciclagem e reutilização quando comparados com remanufatura e Logística Reversa. Isto se dá, porque tais termos estão mais difundidos na linguagem do dia a dia, e há mais tempo também. Por exemplo, o SENAI Paraná (2014) salienta que, desde 1970, o termo reciclagem surge juntamente com a maior exigência referente a preocupação ambiental presente nas empresas.

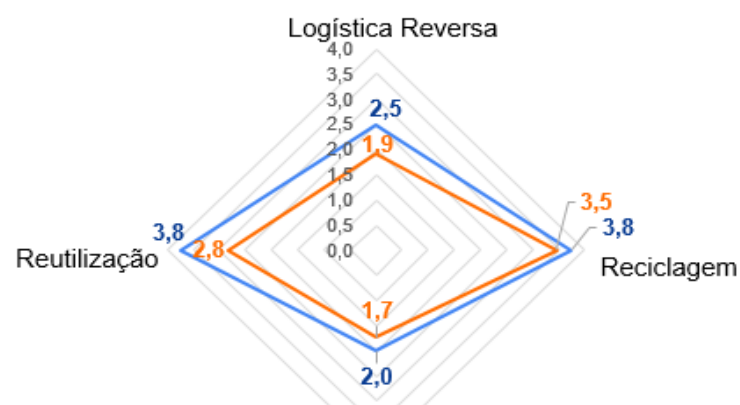

- Grande

Médio Remanufatura

Figura 2. Conhecimento da terminologia relacionada aos resíduos industriais Fonte: Dos Autores, (2020)

Quanto aos resultados com menor intensidade, Logística Reversa e Remanufatura, estes apareceram mais recentemente como "obrigatoriedade", a partir das orientações preconizadas na PNRS/2010 (BRASIL, 2010).

\subsection{Iniciativas de Logística Reversa}

Quanto às iniciativas, observa-se, a partir da Figura 3, é possível verificar que $53 \%$ das empresas possuem alguma iniciativa já implantada.

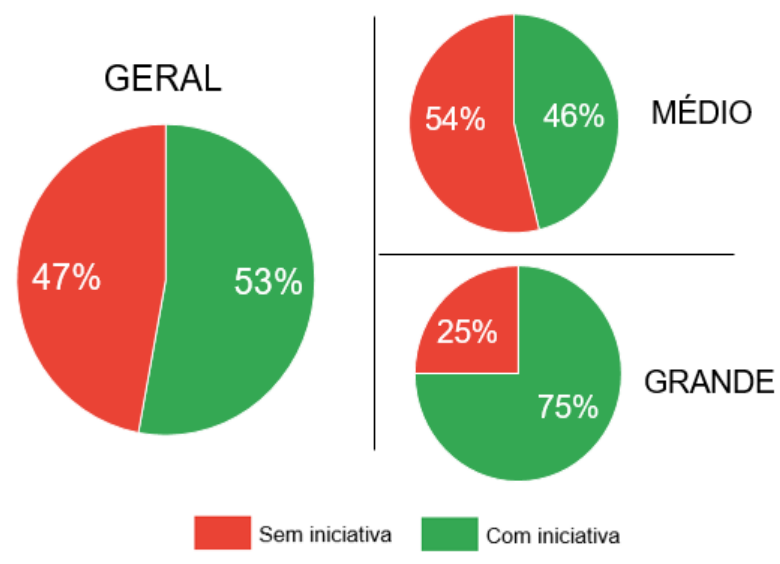

Figura 3. Iniciativas de logística reversa nas indústrias metalmecânicas Fonte: Dos Autores, (2020)
Analisando separadamente, é possível observar que há oportunidades de melhoria para ambos os portes, contudo, nas indústrias de pequeno porte esta diferença é maior. Conforme já mencionado, há muitas barreiras para a implantação de iniciativas de logística reversa (COMPER, 2017), e estas, por vezes, nas indústrias de pequeno porte, fazem com que o processo não se torne contínuo (XAVIER; CORREA, 2013).

\subsection{Análise da prática RECICLAGEM}

Ao abordar a utilização de matéria prima secundária (sucata) em seu processo produtivo, observou-se que, de modo geral, ocorre uma divisão quase simétrica, representada pela Figura 4, demonstrando que aproximadamente $50 \%$ da indústria ainda não realiza a ação.

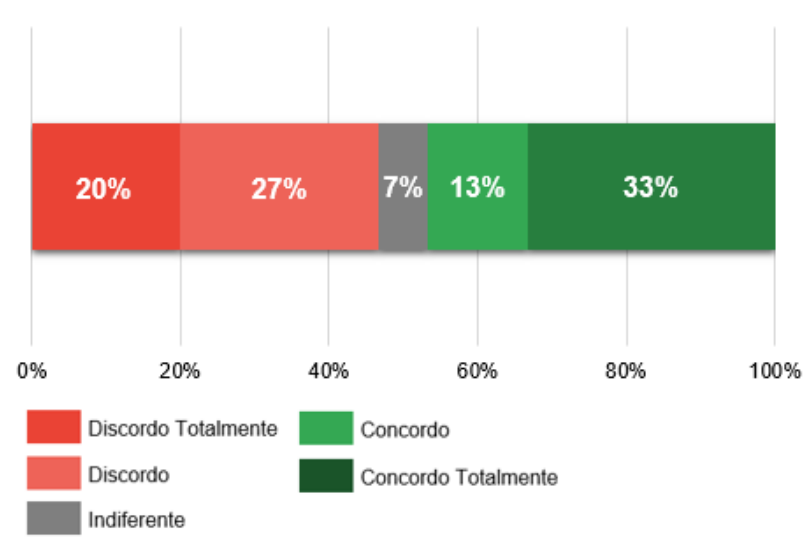

Figura 4. Importância da utilização de matéria-prima secundária em processos Fonte: Dos Autores, (2020)

Ao observar a Figura 5, sobre a transformação de resíduos na empresa, apresenta-se uma grande fragilidade da indústria metalmecânica, pois mais da metade das empresas avaliadas não deixam de fazê-lo.

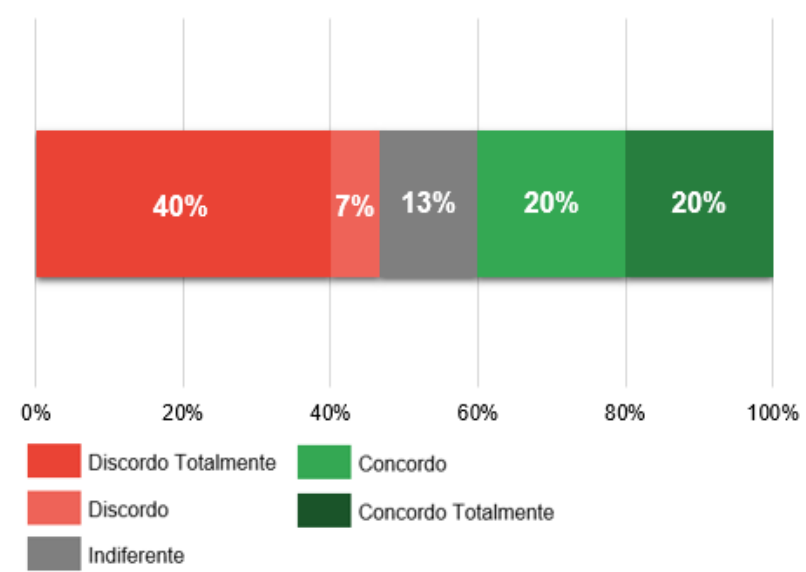

Figura 5. Importância de adoção de processos de transformação de resíduos industriais Fonte: Dos Autores, (2020) 
Para a representatividade da transformação de resíduos na linha de produção, retratada pela Figura 6, aponta-se que mais da metade da população avaliada sequer realiza transformação de resíduos, enquanto apenas $20 \%$ realiza mais que $50 \%$ de transformação de resíduos em sua linha produtiva, frisando assim um ponto crítico e a ser melhorado pela indústria para alcançar eficácia nesta prática.

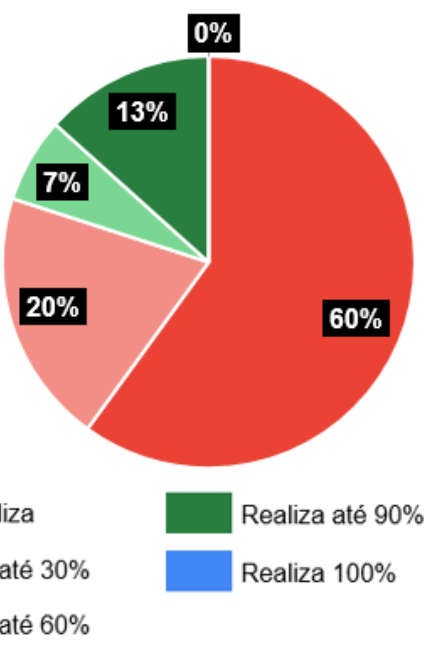

Figura 6. Transformação efetiva de resíduos nas indústrias metalmecânicas Fonte: Dos Autores, (2020)

\subsection{Análise da prática REMANUFATURA}

Quanto à disposição de peças sobressalentes, em que, conforme Figura 7, grande maioria das empresas demonstra que não fornece este tipo de apoio ao cliente.

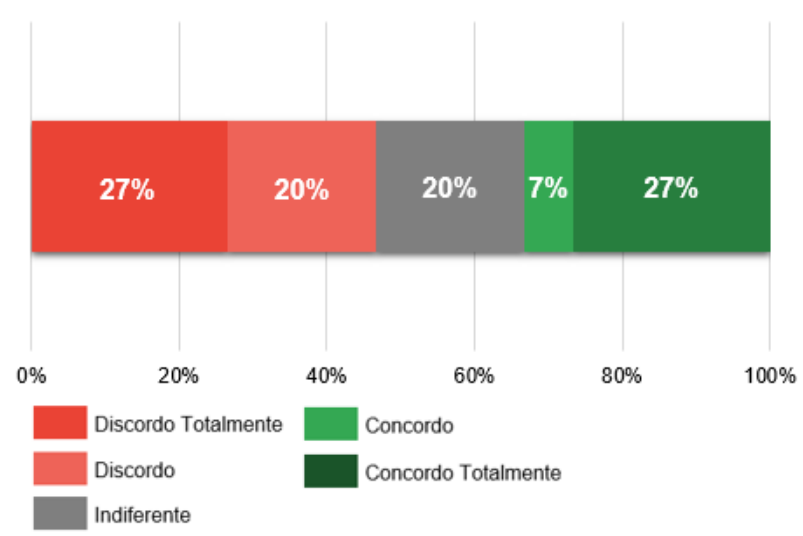

Figura 7. Importância de adoção de práticas de remanufatura na indústria Fonte: Dos Autores, (2020)

Para a questão de realização de reparo e/ou manutenção dos produtos dos clientes, as indústrias apresentam a crença, conforme disposto na Figura 8.

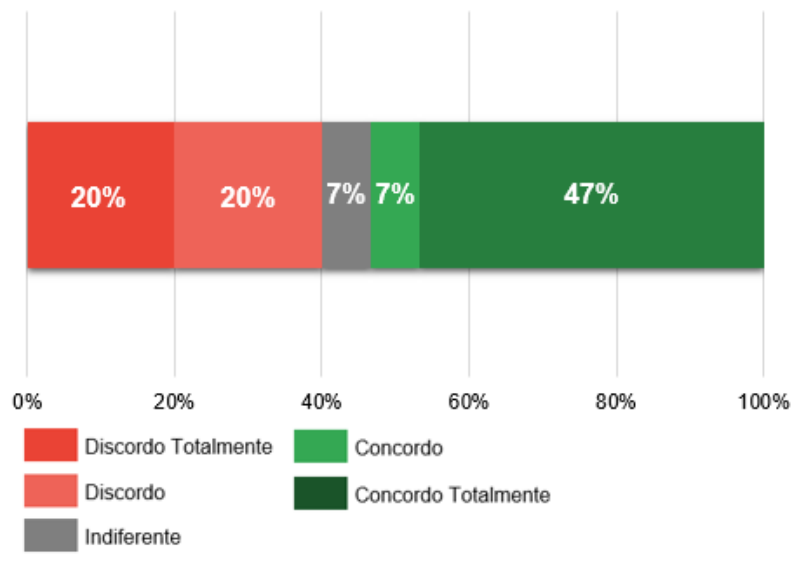

Figura 8. Importância de reparos e/ou manutenção dos produtos pós-venda Fonte: Dos Autores, (2020)

Ainda sobre a Figura 8, na atual situação, a maior parte das empresas busca dar suporte ao cliente no pós-venda, adotando estratégias em incorporação de valor em produtos que apresentem algum defeito, e que possam ser contemplados por alguma garantia ou manutenção de parte do fornecedor (LEITE, 2002).

\subsection{Análise da prática REUTILIZAÇÃO}

Na Figura 9, os respondentes se posicionaram quanto à destinação de resíduos a mercados secundários, o que indica um cenário favorável à esta prática.

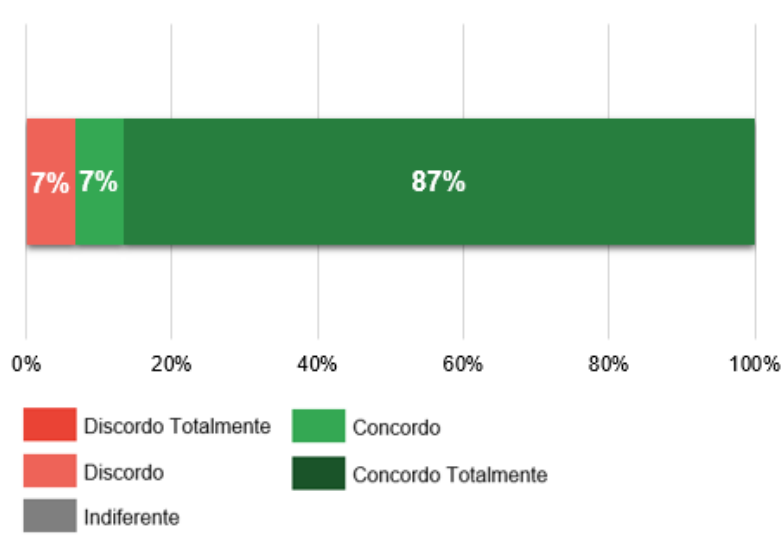

Figura 9. Importância da destinação de resíduos reaproveitáveis a mercados secundários. Fonte: Dos Autores, (2020)

Contudo, o cenário apresentado na Figura 9 implicará também em partes sociais e econômicas, com geração de empregos nestas indústrias secundárias, como a criação de centrais de triagem de materiais recicláveis ou empresas de coleta e transporte de recicláveis.

Quanto ao reaproveitamento de produtos e/ou sucatas, observou-se um "equilíbrio" entre as partes discordantes e concordantes, porém, com uma boa parcela 
respondendo de forma indiferente, o que indica um baixo aproveitamento de produtos que chegaram ao fim de seu ciclo de vida.

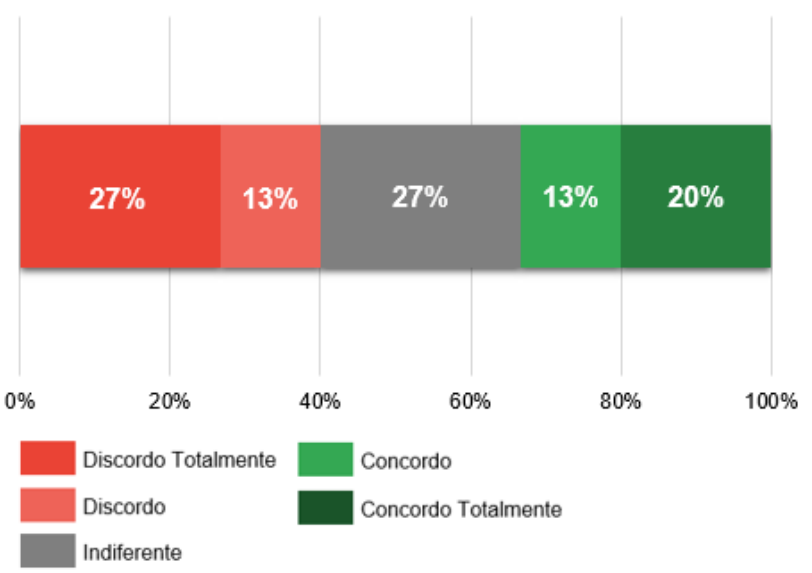

Figura 10. Necessidade de aproveitamento de produtos em fim de ciclo de vida Fonte: Dos Autores (2020)

\section{CONSIDERAÇÕES FINAIS}

De modo geral, no que se refere à transferência de conhecimento entre a empresa e colaboradores, os resultados apontam para uma vulnerabilidade quanto aos conceitos de Logística Reversa e Remanufatura. A problemática se amplia quando se avalia isoladamente as empresas de médio porte.

Cenários como estes dificultam a aplicabilidade de conceitos que envolvam quaisquer iniciativas maiores de Logística Reversa, bem como visualizar seus benefícios. Dentre as principais iniciativas, estão o retorno de embalagens, baterias e ferramentas, materiais que, conforme a PNRS (BRASIL, 2010), obrigatoriamente deverão ser contemplados pela Logística Reversa.

Quanto ao tópico "Reciclagem", os dados indicam que as empresas associadas ao SIMMMEB não fazem o uso de reciclagem dos resíduos gerados a partir de seus processos. Além dos resíduos, os resultados evidenciaram que o recondicionamento de produtos já fabricados não é realizado com frequência, gerando-se alto volume de descarte com baixo reaproveitamento, onde $94 \%$ das empresas destinam seus resíduos a mercados secundários.

Entre os fatos levantados, é possível perceber que, de maneira geral, as empresas de Médio e Grande porte dos municípios de Blumenau, Pomerode e Gaspar do setor Metalmecânico e associadas ao SIMMMEB demonstram conhecimento insuficiente para gerar iniciativas estruturadas que envolvam efetivamente a Reciclagem, Remanufatura e Reutilização.

A partir desta análise, e pela importância do tema, reforça-se a necessidade da atuação do SIMMMEB como agente integrador das empresas, principalmente às de médio porte devido aos resultados negativos, para intermediar a acessibilidade ao conhecimento e sua aplicação.

Para trabalhos futuros, recomenda-se uma amostragem maior tanto em âmbito geográfico quanto em segmento e porte, para que possa ser realizado um comparativo de dados extraídos e avaliar se o segmento ou porte podem interferir nas práticas do tema. Sugere-se uma futura demonstração do nível de maturidade de utilização de LR das empresas bem como mensurações de custos e lucros provindos desta prática.

\section{REFERÊNCIAS}

AMAOMO, A.C.S.;COSTA, B.G.;SILVA, M.S.; SANTOS, R.R.; TEIXEIRA, C.A.C. Logística Reversa nas Metalúrgicas. 2014. Disponível em: <https://www.aedb.br/seget/arquivos/artigos14/10220186.pdf>. Acesso em: 02 mar. 2020.

ARAÚJO, M.C.C.C. Mapeamento da qualidade ambiental nas organizações privadas de santa catarina iso 14000 e produção mais limpa. 2004. Disponível em: <https://repositorio.ufsc.br/xmlui/bitstream/ handle/123456789/87292/224875.pdf?sequence $=1 \& \mathrm{i}-$ sAllowed=y $>$. Acesso em: 15 jun. 2020.

ASSOCIAÇÃO BRASILEIRA DE NORMAS TÉCNICAS (ABNT). NBR 10004 - Resíduos Sólidos - Classificação. Rio de Janeiro, 2004.

BATISTA, D.C. Classificação e caracterização dos resíduos do beneficiamento da sucata de ferro e aço utilizada no processo siderúrgico para identificação de viabilidade de aplicações. 2014. Disponível em: < https://teses.usp.br/teses/disponiveis/18/18138/ tde-18122014-100431/publico/Dissertacao_Daniella_ Cristina_Batista_Versao_Final.pdf $>$. Acesso em: 20 mar. 2020.

BENNEMANN, R.B. Proposta de Gestão Ambiental para Indústria Metal Mecânica. 2012. Disponível em: $<\quad$ http://usuarios.upf.br/ engeamb/TCCs/2012-2/ RAFAEL\%20BATISTA\%20BENNEMANN.pdf>. Acesso em: 25 jun. 2020.

BRASIL. Política Nacional de Resíduos Sólidos. Lei no 12.305, de 2 de agosto de 2010. Presidência da República, Departamento da Casa Civil. Brasília, 2010. CHIZZOTTI, A. Pesquisa em Ciências Humanas e Sociais. 2010. Disponível em: < https://www. academia.edu/38702337/Ant\%C3\%B4nio_ Chizzotti_PESQUISA_EM_Cl\%C3\%8ANCIAS _ HUMANAS_E_SOCIAIS_2a._edi\%C3\%A7\%C3\%A3o_ CORTEZ_EDITORA?auto $=$ download $>$. Acesso em: 20 
abr. 2020.

COMPER, I.C. Barreiras da logística reversa de óleos lubrificantes: uma avaliação utilizando a análise hierárquica de processos. 2017. Disponível em: <http://repositorio.ufes.br/bitstream/10/8447/1/tese_11297_62\%20 -\%20Indiana\%20Caliman\%20Comper.pdf>. Acesso em: 17 jun. 2020.

CORRÊA, A.P.M.O papel dos stakeholders para a efetivação da Logística Reversa: o caso do programa "Mundo Limpo, Vida Melhor". 2013. Disponível em: <https:// repositorio.ufpe.br/bitstream/123456789/10813/1/ DISSERTA\%c3\%87\%c3\%830\%20ANA\%20PAULA\%20 MACHADO\%20CORR\%c3\%8aA.pdf>. Acesso em: 25 jun. 2020

DELALIBERA, P.H.A.; LIMA, R.S.; TURRIONI, J.B. Pesquisa levantamento para análise do modelo de compras conjuntas adotado em arranjos produtivos locais de Minas Gerais. 2015. Disponível em: < https://www.scielo.br/ pdf/prod/v25n2/0103-6513-prod-0103-6513014411. pdf $>$. Acesso em: 20 abr. 2020.

ESMAEILIAN, B.; BEHDAD, S.; WANG, B. The evolution and future of manufacturing: $A$ review. Journal of Manufacturing Systems, v. 39, p. 79-100, 2016.

FEDERAÇÃO DAS INDÚSTRIAS DO ESTADO DE SANTA CATARINA. Guia da Indústria. 2015. Disponível em: $<$ http://ciesc.com.br/centro-das-industrias/guia-da-industria>. Acesso em: 25 fev. 2020.

FEDERAÇÃO DAS INDÚSTRIAS DO ESTADO DE SANTA CATARINA. Relevância da Indústria. 2020. Disponível em: <https://www.observatoriofiesc.com.br/resumo-executivo>. Acesso em: 25 fev. 2020.

FEDERAÇÃO DAS INDÚSTRIAS DO ESTADO DE SÃO PAULO. Resíduos Sólidos. 2020. Disponível em: <https://www.fiesp.com.br/temasambientais/residuos-solidos/>. Acesso em: 25 fev. 2020.

FRASCARELI, F.C.O. Análise da influência da adoção de práticas de Green Supply Chain Management no desempenho ambiental e operacional: estudo de casos. 2014. Disponível em: < https://repositorio.unesp.br/ bitstream/handle/11449/115763/000805671.pdf?sequence=1\&isAllowed=y >. Acesso em: 03 jul. 2020.

INSTITUTO AÇO BRASIL. Relatório de Sustentabilidade 2018. 2018. Disponível em: <http://www.acobrasil. org.br/sustentabilidade/assets/pdfs/A\%C3\%A7o\%20 Brasil\%20\%C2\%BB\%20Completo.pdf>. Acesso em: 20 mar. 2020.

LEITE, P. R. Logística reversa: nova área da logística empresarial. Tecnologística, Ano VII, n. 78, 2002, p.17

MACEDO, A.O.; CAMPOS, R. R. Diagnóstico do complexo metal-mecânico: Brasil e Santa Catarina Revista de Tecnologia e Ambiente, Criciúma, 2001. OLIVEIRA, J.; SEMENSATO, B.I.; MORAES, G.D.A.; FILHO, E.E. Caracterização das pequenas empresas do setor metal-mecânico a partir das dimensões estrutura organizacional e dirigentes. 2012. Disponível em: <https://periodicos.pucpr.br/index.php/REBRAE/article/ view/13733>. Acesso em: 20 jun. 2020.

PEREIRA, André Luiz; et al. Logística Reversa e Sustentabilidade. São Paulo: Cenage Learning, 2012.

REIS, A.C.; CARMO, L.F.R.R.S.; NISHIOKA, I. Logística reversa e práticas correntes no setor de reciclagem. 2009. Disponível em: < https://limpezapublica.com.br/ textos/t7_0080_0050.pdf>. Acesso em: 03 mar. 2020.

SENAI Paraná. Proposta de plano de Logística Reversa. 2014. Disponível em: <http://www.sindimetalnortepr.com.br/files/materiais/material-062719000000-27102015.pdf >. Acesso em: 20 Ago. 2020.

SILVA, A.P. Proposta e Implantação de um plano de gestão de resíduos sólidos em indústria do setor metal mecânico. 2013. Disponível em: < https://www.lume. ufrgs.br/bitstream/handle/10183/114960/000955779. pdf?sequence=1>. Acesso em: 27 jun. 2020.

SILVA, F.L. Práticas de logística reversa com base nos relatórios de sustentabilidade de empresas brasileiras. 2014. Disponível em: < https://repositorio.ufsc.br/ xmlui/bitstream/handle/123456789/129026/328107. pdf? sequence=1\&isAllowed=y $>$. Acesso em: 05 Ago. 2020.

XAVIER, L. H.; CORRÊA, H. L. Sistemas de Logística Reversa: Criando cadeias de suprimentos sustentáveis. São Paulo: Editora Atlas S. A, 2013. 


\section{AUTORES}

ORCID: https://orcid.org/0000-0002-2496-6235

JOEL DIAS DA SILVA, Dr. | FURB - Universidade Regional de Blumenau | Departamento de Engenharia de Produção e Design | Blumenau, SC - Brasil | Correspondência para: Rua São Paulo, 3250 - Itoupava Seca, Blumenau - SC, 89030-000 | 4-mail: joels@furb.br

ORCID: sem orcid

LUIZ BERNARDO BRAUN PREBIANCA | FURB - Universidade Regional de Blumenau | Departamento de Engenharia de Produção e Design | Blumenau, SC - Brasil | Correspondência para: Rua São Paulo, 3250 - Itoupava Seca, Blumenau - SC, 89030-000 | e-mail: Iprebianca@ furb.br

\section{COMO CITAR ESTE ARTIGO}

PREBIANCA, Luiz Bernardo Braun; SILVA, Joel Dias da. Logística Reversa Na Indústria Metalmecânica: O Caso Das Indústrias Em Blumenau, Pomerode E Gaspar (SC). MIX Sustentável, [S.I.], v. 7, n. 4, p. 39-48, set. 2021. ISSN 24473073. Disponível em:<http://www. nexos.ufsc.br/index.php/mixsustentavel>. Acesso em: dia mês. ano. doi:https://doi.org/10.29183/2447-3073. MIX2021.v7.n4.39-48. 
